\title{
Research on the Impact of Credit Value on Enterprise Development
}

\author{
Dezhong $\mathrm{Li}^{1}$, a \\ ${ }^{1}$ Rongzhi College of Chongqing Technology and Business University, Chongqing, China, 401320 \\ ${ }^{2}$ Chongqing bai da hui Enterprise Credit Service Co., Ltd, Chongqing, China, 401320 \\ aemail,
}

Keywords: Credit Value, Enterprise Development, Influence

\begin{abstract}
In many countries in the West, the value of corporate credit in this regard is very important, on the current situation in China with the deepening of the market economy and anti-credit behavior for the punishment is more and more serious, many enterprises have gradually attached importance to the credit value stand up. Modern enterprise development is the goal of survival is to maximize the value of the company, in such circumstances, how to use the credit management to the value of the company to achieve, it has become the enterprise to complete the goal. This article is mainly to explore the impact of credit value on the development of the company.
\end{abstract}

\section{Introduction}

From the current form of market economy, its main form is the credit economy, in the process of continuous development of the market economy and credit is a normal operation of its basic criteria, but also enterprises in the development process to follow the moral concept. Now the market information is changing rapidly, the economic situation is changing and in this case, the enterprise management has become a normative corporate behavior and the development of a strong guarantee for the market economy, while it is also a modern enterprise in the management process of key content and links. The development of enterprises has a very important impact. Affect the business goals can be achieved, related to the company's value can be achieved.

\section{Related Knowledge Analysis of Credit Value}

Credit Management. Enterprise credit value wants to play its role, what it needs to do is to carry out its credit management. Often the enterprise credit management is divided into narrow sense and broad sense, this article refers to the credit management is the kind of broad sense. The so-called credit management is to give others credit and get someone else's credit for an activity. Is the business integrity of corporate behavior and corporate credit transactions in a comprehensive management [1]. It involves a lot of aspects of the content, including business and enterprise employees, suppliers, customers, the public, insurance, banking, government between the various credit behavior. The credit behavior between the enterprise and the government is manifested in the enterprise's compliance with the relevant laws and regulations, and the credit behavior in the enterprise and the employee is mainly reflected in the enterprise's ability to timely distribute the wages to the employees at the same time to provide some development opportunities for the employees. And customer's credit behavior is reflected in the follow-up in the after-sales service, settlement methods and product quality and other aspects of the customer made a variety of commitments; business and bank behavior between the main performance for the enterprise will timely repayment; business and the public the performance of credit between the performance of various donations, environmental protection and other social responsibility; business and suppliers between the performance of credit behavior for the purchase of raw materials when the time will pay off the relevant accounts in time. 
The Generation of Credit Value. The credit value of the enterprise is mainly due to the participation of many economic entities, mainly in the following aspects: (1) From the main elements of the composition of the credit value, the market, the credit side and the recipient side is the main constituent elements among these elements, the credit side is also a petition is the formation of value and the realization of the two major economic entities. If there is any one of the missing, there is no way to produce credit value [2]. (2) The business objectives set by the enterprise is to make credit value to produce a decisive factor only the pursuit of business in the pursuit of maximizing the time will pay attention to mining development of credit value. (3) The credit side of the recognition of the value of credit and recognition is the enterprise to achieve the credit value of another factor, the credit side of the credit value of the more recognized, then the credit value of the opportunity to be improved will be greater.

\section{The Impact of Corporate Credit Value on the Development of the Company}

The Impact of Corporate Credit Management on the Development of the Company. Enterprise services are also produced by those products that need to be sold to customers can achieve its value, this time the customer also want to buy their own products and business commitments are consistent. Enterprises in the credit management will involve the following aspects of the content: (1) Business managers to give their own image a certain understanding of the need to advocate the development of credit culture within the enterprise, so as to improve the enterprise's credit rating, so that enterprises can better establish the image, the service and products can be truthfully passed on the customer, so customers will be more trusted business [3]. (2) Enterprises in order to increase the market share of the road, so that sales have been improved to a certain extent, you need to sell the credit when the implementation of credit and other forms of credit to complete, so companies need to develop a number of credit policies to standardize the management of credit sales.

The Impact of Enterprise Credit Management on the Development of the Company. Enterprises in order to its production and operation can be carried out smoothly and you need to continue to buy from the supplier to produce the material of the product. If the credit rating of the enterprise is high, the trust of the supplier can be obtained, and then the foreseeable approach can be used to deal with the relevant issues, such as credit sales, improve the kind of transaction efficiency between suppliers and enterprises, reduce and supply business contract between the funds spent, so that both sides of the transaction costs can be reduced a lot, there is a strong brand effect to enable enterprises to enhance the ability to bargain. Enterprises and suppliers generated between the credit and other similar business behavior cannot only reduce the working capital of enterprises, increase the efficiency of capital turnover, reduce material costs and procurement costs [3]. But also to allow corporate debt costs and other kinds of transaction costs to a certain extent be reduced, there will reduce the financing of enterprises there are business uncertainty, and then and suppliers can establish a good relationship and may establish a long-term cooperative relationship to the long-term development of enterprises laid a certain foundation.

The Impact of Bank's Credit Management of Enterprises on the Company's Development. Enterprises in the investment funds, and then run the funds there are out of this process, because the reasons for the emergence of a very easy to make enterprises into a difficult situation of cash flow. In order to allow enterprises to normal production and operation, companies need to borrow. Banks are a subject of contemporary credit system, one of which is an important function of credit intermediaries, so enterprises in the financial problems when they will find bank loans [4]. Many commercial banks are now in order to reduce the risk of corporate loans before they will be assessed credit, the bank will be based on the credit level of the enterprise to lend. The higher the firm's credit, the less it will be. It will be better to promote the company's development.

The Impact of Business-To-Employee Credit Management on the Company's Development. Enterprise value is created by the employees of the enterprise, which can be seen in order to obtain the development of employees in which a very important role. Credit management of employees will not only have an impact on the production and operation of enterprises, but also related to the 
realization of corporate value. Enterprises and employees to show the credit behavior has the following aspects: (1) Enterprise employees in accordance with the relevant requirements of production and management to complete the target tasks and production processes, companies will need to pay the corresponding salary compensation to employees [5]. (2) Enterprises should also be fulfilled to employees and enterprises in the work of the expected environment, personal development expectations and other aspects of a written contract or a psychological contract commitment. Enterprises fulfill the commitment to the staff of the various benefits and benefits and other aspects of the various credit acts, but these actions need to pay a certain cost, such as training fees, wages, etc., which will allow enterprises to increase the cost of investment, so that reduced cash flow.

The Impact of Corporate Credit Management on the Development of the Company. Enterprises in the production and operation of the macro environment is the socio-economic, business-to-society credit management is mainly reflected in the implementation of various social responsibility and tax law. According to the law is reflected in the tax is a legal effect of credit, from a certain level of taxation is a mandatory act, if the enterprise tax evasion will be sanctioned by the law, so that there is no business value to achieve the enterprise developed. In the implementation of social responsibility, there are relevant economists that the economic performance of enterprises and enterprises need to bear the relationship between social responsibility is a positive correlation [6]. Enterprises to fulfill the relevant social responsibility are conducive to its image, but more people have a sense of identity to their products. In the value card model, the value of the enterprise is the enterprise's services, products and brands together to achieve, from here we can see that in order to achieve the company's value, the brand is one of the factors that cannot be ignored, it is intangible resources promote enterprises to better development.

The credit behavior of the enterprise to the customer will have some influence on the bad debts, the receivable turnover rate, the receivables, the cash flow, the sales growth rate and the sales heat. The credit comfort generated between the firm and the supplier will have an impact on the financing capacity of the firm and change its original capital structure. Thus reducing the amount of money shipped. Corporate and internal employee credit behavior can be expressed through the service profit chain to the impact of financial performance. Business and government public credit behavior can allow enterprises to be recognized by the community, so that it can establish a good brand in the community there is the impression that the brand and the image of such intangible assets in the company's development process will have a very important role. Therefore, it needs for this regard to give some attention.

\section{The Method of Enterprises Cultivating Credit Value}

Cultivating human capital, intellectual property, innovation ability and credit and other kinds of intangible assets value has become the enterprise to obtain competitive advantage, survival and development of the key points. However, from the current situation of Chinese enterprises, the enterprise development and use of their own credit resource value awareness is still very weak. Therefore, enterprises need to proceed from the following aspects, dig out their own credit value, and then allow enterprises to enhance the financing capacity and ultimately to enhance the competitiveness of enterprises to promote the development of enterprises.

Training Managers Related Credit Awareness and Establish Credit Culture. In many developed countries, the credit payments between their enterprises have exceeded eight percent [7]. This means that the credit has the ability to create value has exceeded any other kind of assets to create the value of the creation. But the current many enterprises in China because of weak credit awareness of malicious fraud, arrears of loans and other things, corporate credit value is ignored by many people and its direct impact on the enterprise is difficult to finance its financing difficult. Enterprises to establish a credit value, the first thing to do is to change the concept of managers, through the establishment of the cultural system within the enterprise, formed on the management level, down to the employees agree with the potential value of credit value capacity of the phenomenon, so as to allow enterprises among the staff in the process of external exchanges on the 
corporate credit will consciously maintain, and ultimately achieve the purpose of enhancing corporate credit value.

Establish the Managerial Mechanism Related to Credit Behavior. Corporate credit value comes mainly from the repeated transactions, in other words, only enterprises in the pursuit of long-term development and cooperation will pay attention to the value of credit [8]. But in a very clear enterprise, managers and owners are in a state of separation, so that there will be some high-level managers because of the short-term benefits of the pursuit of potential resources to ignore the development of the phenomenon. This shows that the business owners need to establish a set of enterprises to cultivate credit value and the vital interests of managers associated with the incentive mechanism, which will enable managers to take the initiative to develop the development of corporate credit potential a variety of value, and then to the enterprise to maximize the benefits.

Increase the Corresponding Punishment for the Dishonest. From the relevant data can be known. Chinese annual economic contract is about 400,000 copies, in which the implementation of these commitments only half of the commitment each year because of evasion of debt to the credit side of the economic losses of up to 180 billion RMB, which seriously affected the market economic transactions in the normal order [9]. From the enterprise to form the value of credit and the realization of the value of this process, the enterprise to achieve its credit value depends on the trading unit from the hungry man to each other whether the economic identity of its credit value. Therefore, the outside of the enterprise need to strengthen the supervision of various corporate credit behavior, but also need to establish a corresponding punishment mechanism for those who are not to be important to punish those who will pay attention to their own credit value.

\section{Conclusion}

In the current situation, the level of credit management in the enterprise is not high and the lack of credit is very serious. In this case, enterprises should pay attention to mining credit value, pay attention to credit management, so as to enable enterprises to establish more in the community good image, expand its brand effect, improve the economic efficiency of enterprises, and thus promote the enterprise can be more stable and stable development.

\section{References}

[1] Yin Qi month. Credit value and financing sustainable development of small and medium-sized enterprises[J]. Commercial Research, 2013, (05): 73-80.

[2] Du Lihui. Enterprise development strategy on the impact of credit capacity[J]. Metallurgical Economics and Management, 2012, (06): 14-20

[3] He Pinghua, Ling Yuanyun, Zhou Deyi. Food value chain and its impact on quality and safety credit behavior of food enterprises [J]. Agricultural Economics, 2009, (01): 48-52 + 111 .

[4] Chen Junyan. Small and medium-sized enterprise credit value evaluation and credit rating evaluation[J]. Shandong University of Science and Technology, 2004

[5] Dong Yurong. Corporate credit spreads and macroeconomic fluctuations [D]. Nanjing University of Finance and Economics, 2014

[6] Chang Yi. CreditMetrics model based on Chinese credit portfolio credit risk measurement[D]. Southwest University of Finance and Economics, 2013

[7] Tian Yuanyuan. Empirical Study on the Factors Influencing the Credit Spread of Chinese Enterprise Bonds[D]. Southwest University of Finance and Economics, 2013

[8] Lu Yanlu. Commercial credit, corporate cash holdings and regional financial development [D]. Southwest University of Finance and Economics, 2013 
[9] Mo Jun. On the impact of corporate credit management on corporate value[J]. Management Manager, 2011, (23): 120. 